\title{
Repeating the target neither speeds nor slows its detection: Evidence for independent channels in letter processing
}

\author{
LESTER E. KRUEGER and RONALD G. SHAPIRO \\ The Ohio State University, Columbus, Ohio 43210
}

\begin{abstract}
A target letter at a predesignated location typically is identified less readily when extraneous letters are added to the display. This disruption has been attributed to lateral interference via interactive or inhibitory channels or to attempts to encode the string as a unit. In the present study, subjects saw a single letter (e.g., B), a repeated-letter string (e.g., BBBB), or an extraneous-letters string (e.g., BCLD) and had to decide whether the leftmost letter in the string matched a target letter. Since trials were blocked by string type, letter position did not have to be discriminated on repeated-letter trials, nor was response competition present on those trials. With normal letter spacing, RT was virtually the same on repeated-letter trials as on single-letter trials. (Increasing the letter spacing in Experiment 3 did produce a slight, but nonsignificant, 22 -msec increment on the repeated-letter trials.) The results indicate that individual letters are perceived as such just as well when presented in a group as when presented individually and thus provide support for the parallel, independent-channels model.
\end{abstract}

What happens to a target letter when it is embedded in a string of letters? Does it maintain its independence and integrity? Some investigators have proposed that letters in a multiletter display are encoded by parallel, independent channels (e.g., Eriksen \& Spencer, 1969; Gardner, 1973; Shiffrin \& Geisler, 1973). However, other investigators have proposed that the individual letter is readily masked by, or merged with, the neighboring letters. Bjork and Murray (1977) and Estes $(1972,1974)$ depicted the various letters in a display as encoded on interactive or mutally inhibitory channels. Johnson $(1975,1977)$ depicted the central processor as attempting first to form a single unit or pattern out of the letter string, leaving until later any analysis of individual letters. If the letter string formed a word, then a unitary label or interpretation would be applied to it, whereas if it formed a nonword or nonsense string, "there would be several initial attempts to encode it as a unit, followed by a parse and a serial encoding of the letters" (Johnson, 1977, p. 118). If a single letter was presented by itself, on the other hand, it would be immediately encoded as a letter.

The issue seems simple to test. Just have subjects decide whether a critical letter is one target letter

This study was supported in part by NIMH Grant MH32295. The authors are grateful to Cheryl Lawton, Gloria Natter, Cynthia Reagan, Steve Rogers, and Dennis George for assistance in collecting the data, and to Neal F. Johnson for very useful discussions. Requests for reprints should be sent to Lester E. Krueger, Ohio State University, Human Performance Center, 404-B West 17th Avenue, Columbus, Ohio 43210. (e.g., T) rather than another (e.g., F). Present the critical letter by itself on some displays, but embed it in a group of letters on other displays. In one variant of this procedure, the location of the critical letter might be predesignated, so that some of the context letters might themselves be instances of a target letter and thus more difficult to ignore. Not surprisingly, with both of these procedures, as many studies attest, subjects perform much better when the critical letter is presented alone.

The critical letter might yet be just as visible in the multiletter string as when presented alone, however. The added, neighboring letters might only disrupt processing that occurs after the encoding stage. If the location of the critical letter is not predesignated, then the neighboring nontarget letters, when misidentified as the alternative (absent) target, might distort the decision reached (e.g., Eriksen \& Spencer, 1969; Gardner, 1973; Shiffrin \& Geisler, 1973). Even when the critical letter's location is predesignated and the main decision is based on it, the neighboring letters can be instances of the alternative target and thus might produce response competition with the critical letter (Eriksen \& Eriksen, 1979; Eriksen \& Schultz, 1979; Taylor, 1977). Even if the added letters are largely inhibited, since they do not occupy the predesignated position, they may yet offer lively response competition insofar as they are processed by parallel, independent channels, and the person cannot divert processing capacity or attention from them (Shiffrin \& Geisler, 1973). 
To prove that the added, neighboring letters disrupt the encoding stage, the possibility that they disrupt the decision or response stage instead must be excluded. One way to exclude the possibility of response competition is to make the added letters identical to the critical letter in the predesignated position. Adding identical letters ought to aid rather than hurt processing at the decision or response stage. If performance is harmed nevertheless, however, then it must be concluded that the added letters disrupt an earlier stage or stages, possibly encoding. (An early effect would be just as likely to involve comparison as encoding, though. It might simply be more difficult to compare a letter with a five-letter string, say, than a letter with a letter, or a five-letter string with a five-letter string; cf. Massaro \& Klitzke, 1977; Sloboda, 1977.)

In recent tests, adding identical letters still produced some interference. Eriksen and Schultz (1979, Experiment 1) found that response time (RT) was $20 \mathrm{msec}$ longer for repeated-letter displays than for single-letter displays, though Eriksen and Eriksen (1979, Experiment 1) found no increment at all. Johnson (1977) obtained an increment that exceeded $100 \mathrm{msec}$, but in subsequent, unpublished work, he has found the increment to range between 20 and $30 \mathrm{msec}$ (Johnson, Note 1). Johnson (1977) said that the increment should not have occurred "if the subjects were simply responding on the basis of the first letter processed"' (p. 120) and that "the effect does seem consistent with a view that subjects first attempted to encode the entire fiveletter array as a unit, with letter identification occurring only after those attempts had failed" (p. 120).

In the three studies just cited, however, the repeatedletter displays were intermixed with extraneous-letters displays, whose added letters differed from the critical letter. This meant that subjects always had to discriminate both form and location, in order to disregard the input from the nonpredesignated locations, which might be extraneous and misleading (Eriksen \& Schultz, 1979). Even single-letter displays took somewhat longer to process when they were intermixed with, rather than blocked separately from, extraneous-letters displays (Eriksen \& Eriksen, 1979; Eriksen \& Schultz, 1979). This finding "supports the hypothesis that subjects introduce an inhibitory stage into their behavior when they anticipate noise stimuli along with the target"' (Eriksen \& Schultz, 1979, p. 257).

If trials are blocked by display type, however, then on single-letter and repeated-letter displays the subject need not discriminate location as well as form, but may confidently respond to the first form discriminated, regardless of location, since all letter(s) present are, in effect, equally critical. Eriksen and Eriksen (1979, Experiment 2) blocked trials by display type, and they found RT was as fast when the added letters were physically similar to the critical letter and were compatible with it (i.e., signaled the same response) as when the critical letter appeared alone.
In the present study, likewise, trials were always blocked by display type.

The blocking factor also may help to illuminate some results involving accuracy rather than RT. Bjork and Murray (1977) asked subjects to identify the letter that appeared in the cued column of a fourcolumn matrix. The letter was identified more accurately (and faster) if it appeared alone (i.e., the rest of the matrix was filled in with number-sign characters) than if it was repeated in an uncued column. Trials were not blocked in this study, however, so subjects never knew beforehand whether the added letter on a particular display would be the same as the critical letter, the alternative target letter, or just be a neutral letter. The subjects were faster, but made more errors, when the added letter matched the critical letter rather than the alternative target letter. Bjork and Murray attributed the greater decrease in accuracy on repeated-letter trials to greater lateral interference when the neighboring letter was identical to the critical letter, and they proposed a featurespecific inhibitory channels model. However, more than the feature-extraction stage seems to be involved, because Egeth and Santee (1980) found that even an added letter that was identical in name but not in shape (e.g., "e" was added letter, "E" was critical letter) hurt recognition accuracy more than did the corresponding version of the alternative target letter (e.g., "a" was added letter).

Perhaps what was difficult to discriminate on Bjork and Murray's repeated-letter trials was the location, not the form, of the letters. When two letters are set side by side, it may be more difficult to localize them in distinct positions if they are identical at either the physical level or the name level. Eriksen and Lappin (1965) excluded the location factor by always adding identical letters to the display and not predesignating a location for the critical letters. In their case, accuracy of identification increased, rather than decreased, as more letters were added.

The Eriksen and Lappin results suggest that RT as well as errors might be decreased by repeating the target letter. However, other findings indicate that little or no such gain can be expected. Eriksen and Eriksen (1979, Experiment 2) found no difference in RT between single-letter trials and those on which the added letters signaled the same response as the critical letter. Estes (1972) found that the correct identification of the target element (embedded at random among extraneous elements), when corrected for guessing, became faster as the number of redundant target elements increased (and thus the number of extraneous elements decreased), but Bjork and Estes (1971) and Wolford, Wessel, and Estes (1968) found that the corrected RT was independent of the number of redundant target elements. Furthermore, unlike the typical accuracy study, the letters in the present study were presented far above threshold, and Garner (1974) 
reported that the redundancy provided by repeated items only speeds processing which is state limited (i.e., near threshold). [On the other hand, Egeth and Santee (1980) suggested that repeated letters are more likely to facilitate than to inhibit performance when the display is presented for a long duration and in a nondegraded manner.]

\section{EXPERIMENT 1}

In the present study, the subject first saw a target letter and then had to decide whether the leftmost position of the letter string shown next was identical or not with the target letter. Experiment 1 contained four types of displays, each presented in a separate block of trials: (1) single letter, (2) repeated letter (i.e., all letters in the display were identical), (3) nonword, and (4) word. The reason for using repeatedletter displays has already been discussed. Nonword and word displays were used in order to test whether words, as familiar patterns, conceal, rather than reveal, their component letters. Johnson (1977) postulated that when presented with a word or a nonword, a person would first attempt to encode the string as a unit. The attempt would succeed with a word, but not with a nonword, which would then be parsed and its letters encoded. Letter search thus ought to be faster with a nonword than with a word. The fact that, on the contrary, letter search typically is faster with words than with nonwords (Henderson, 1975; Krueger, 1975) might seem to disconfirm this prediction, but in the typical letter search study the location of the target letter is not cued. Words thus might be searched faster, not because the target letter is seen more clearly in them, but because its location is determined more accurately (e.g., Krueger \& Shapiro, 1979). When the location of the target letter is precued, on the other hand, performance typically is no better for words than for nonwords (Johnston \& McClelland, 1974; Silverman, 1976, 1977; Sloboda, 1976; see Krueger's, 1975, review). Words might even make their letters qua forms more difficult to see, either because the word as a unitary whole might tend to swallow up its letter components or because the recognition response to the word might tend to compete with the recognition responses to the letters. Krueger and Shapiro (1979), however, found that letter mutilations are detected as well in words as in nonwords. In any case, the present study provided an additional test to determine whether the word superiority is not merely eliminated, but reversed, when the location of the target letter is predesignated.

\footnotetext{
Method

Equipment. Uppercase letters were presented at a $60-\mathrm{Hz}$ refresh rate and at $32 \mathrm{~cd} / \mathrm{m}^{2}$ intensity on a cathode ray tube having a greenish-tint, fast-decay P31 phosphor (decay to $1 \%$ intensity at $.25 \mathrm{msec}$ after display offset) by an Imlac PDS-4 graphics computer, which measured RT to an accuracy of $1 \mathrm{msec}$. (The
}

intensity was measured with closely spaced lines in a special test patch). The letters, presented as thin, illuminated lines on a dark screen, were software generated. Each subject sat alone in a dark room, with the head held fast in a chinrest located $70 \mathrm{~cm}$ from the display screen.

Stimulus materials. A $1.6 \mathrm{~mm}$ wide $\times 1.6 \mathrm{~mm}$ high plus sign centered on the screen was the fixation point. The plus sign was $.8 \mathrm{~mm}$ below the letters displayed. Either one or four letters were displayed at one time. The single letter or the leftmost letter of the multiletter string had its left edge aligned with the vertical line of the fixation plus sign. The target letter also occupied this position when it appeared alone at the beginning of the trial. Each letter was $1.6 \mathrm{~mm}$ wide $\times 2.4 \mathrm{~mm}$ high, and $.5 \mathrm{~mm}$ separated adjacent letters in the four-letter display, whose total width was $7.9 \mathrm{~mm}$ (.6 deg of visual angle). The letters were made very small in order to be comparable in size to Johnson's (1975) typed letters.

The 468 trials in an experimental session consisted of 117 displays each of the following four types of display: (1) single letter, (2) repeated letter, (3) nonword, (4) word. All multiletter displays contained four letters, which were all identical in the repeatedletter string, but all different in the nonword and word strings. The beginning (leftmost) letters of the 117 displays of each type consisted of nine each of the following 13 consonants: B, C, D, $\mathrm{F}, \mathrm{G}, \mathrm{H}, \mathrm{L}, \mathrm{M}, \mathrm{N}, \mathrm{P}, \mathrm{R}, \mathrm{S}, \mathrm{T}$. The words were common words having an $A$ or $A A$ rating on the Thorndike and Lorge (1944) word count; the words beginning with $B$, for example, were BASE, BENT, BEST, BLOW, BOAT, BORE, BURY, BUSH, BUSY. The nonwords were formed by randomly permuting the letters within each of the four letter positions of the words, and they thus had the same letter profile at each letter position as the word set.

Each set of 117 displays formed a separate block. There were four different orders of blocks, with nine subjects receiving each, so that each display type appeared equally often as the first, second, third, or fourth block in the session. The order of the 117 displays within each block, as well as the sequence of match and mismatch trials, was randomized afresh for each of the four orderings. Each new block in a session was preceded by a 2-sec message on the screen: "Change in display type." The first 13 displays within a block were regarded as practice; data are reported here only for the 104 regular trials, on half of which the target letter, shown beforehand, matched the leftmost letter of the display. On the other half of the trials ("catch" trials), the target letter was selected at random from the 13-consonant set $(B, C, D, F, G, H, L, M, N, P, R, S, T)$, with the constraint that it differ from all letter(s) in the display.

Procedure. A circle appeared at the center of the screen before each trial to signal the subject to press a footpedal to initiate the trial. After pressing the footpedal, the subject saw: (1) target letter and fixation mark (plus sign) for $1 \mathrm{sec}$, (2) the fixation mark alone for $1.5 \mathrm{sec}$, (3) the display (single letter, repeated letter, nonword, or word) and fixation mark for $1 \mathrm{sec}$, and (4) the fixation mark alone for indefinite duration. A response immediately terminated the trial, and a 2.5 -sec feedback message indicated whether the response had been correct or not. The subjects were told to keep their eyes on the fixation mark at all times and to base a decision solely on whether the first or leftmost letter of the display matched the preceding target letter. They were asked to respond as rapidly as possible, but to make very few errors.

Half of the subjects pressed a left-hand button if they detected a match ("yes") and a right-hand button if they detected a mismatch ("no"), and the other half had the reverse response assignment. Trials with RT greater than $3 \mathrm{sec}$ or less than $200 \mathrm{msec}$ were discarded prior to data analysis; mean RT was computed for correct trials only.

Subjects. Thirty-six Ohio State University undergraduates participated as subjects in order to receive credit in an introductory psychology course. Data from several additional subjects were discarded because of failure to follow the instructions or because of equipment failure. All subjects had at least 20/30 vision (corrected) as tested with a Snellen chart. 


\section{Results}

As Table 1 shows, RT was significantly shorter on "yes" (match) than on "no" (mismatch) trials $[739$ vs. $777 \mathrm{msec} ; \mathrm{F}(1,32)=12.81, \mathrm{p}<.01]$ and on noextraneous-letters trials (single-letter and repeatedletter conditions combined) than on extraneous-letters trials (nonword and word conditions combined) [746 vs. $771 \mathrm{msec} ; F(1,32)=7.14, p<.025]$. There were no significant interactions on RT and no significant main effects or interactions on errcr rate (see Table 1).

Separate analyses also were made within the extraneous-letters and the no-extraneous-letters sets. Mean RT was lower, but not significantly so, on nonword than on word displays [759 vs. $783 \mathrm{msec}$; $F(1,32)=1.47$, n.s.], and error rate was higher, but to only a marginally significant extent, on nonword than on word displays $[3.50 \%$ vs. $2.78 \% ; F(1,32)=$ $3.82, \mathrm{p}<.10$ ]. Mean RT was virtually identical on single-letter and repeated-letter displays [745 vs. $747 \mathrm{msec}, \mathrm{F}<1]$, as was error rate as well [2.94\% vs. $2.81 \%, F<1]$. Separate comparisons between individual conditions revealed only one significant result. Mean RT was significantly lower for the singleletter condition than for the word condition [745 vs. $783 \mathrm{msec} ; \mathrm{F}(1,32)=4.12, \mathrm{p} \approx .05]$.

\section{Discussion}

With trials blocked by display type, no change in RT occurred for repeated-letter displays, as compared with single-letter displays. Location could safely be ignored on blocks containing repeated-letter displays, with a response being triggered as soon as any letter, regardless of location, was resolved. It is conceivable that adding identical letters in the repeated-letter display both helped and hurt processing, with the two effects exactly cancelling out each other and thus producing no net change in RT. The added letters might have hurt processing by introducing lateral interference or a potential pattern unit. They might have helped processing by reducing the expected completion time for the first letter to be resolved, assuming that the letters were resolved in parallel at a variable rather than constant rate. More likely (and more parsimoniously), these opposing effects simply did not occur, and the added letters were processed at approximately the same constant rate as the leftmost presented alone. Eriksen and Eriksen (1979,
Experiment 2) also found no change in RT when compatible letters were added. Furthermore, in several experiments by Estes in which location was not restricted to a predesignated or cued position, the estimated latency of true detection responses (obtained by correcting for guessing) likewise was found to be independent of number of redundant signal elements in some cases (Bjork \& Estes, 1971; Wolford, Wessel, \& Estes, 1968), though not in others (Estes, 1972).

Location could not be ignored on the word and nonword blocks, however, because there the letters added in the rightward positions provided unreliable, extraneous information. Mean RT, but not errors, increased on these blocks, as compared with the single-letter and repeated-letter blocks, which indicates that the subjects were slowed by the added letters but still were able to base their decisions on the leftmost position. Some evidence suggests that RT increased not merely because of the need to discriminate location as well as form, but also because the added letters had some influence on the final decision via response competition. The subjects had to delay responding on word and nonword displays until the leftmost position had been resolved and discriminated. As a result, several extraneous, added letters might typically have been identified simultaneously with or before the critical letter. The leftmost location was precued, but the four-letter display was only .6 deg wide, and it fell within the irreducible minimum extent, on the order of $1 \mathrm{deg}$, to which attention may be narrowed or focused (Eriksen \& Hoffman, 1973). The extraneous letters in words and nonwords never matched the target letter. Thus, on "no" trials, where neither the leftmost letter nor the added letters matched the target letter, the added letters actually were congruent or compatible with the correct response. Only on "yes" trials ought the added letters to have produced response competition. Although the YesNo by Extraneous vs. No-Extraneous interaction on RT was not significant, the results did fall in the expected direction, given response competition. Adding extraneous letters increased RT by $35 \mathrm{msec}$ on "yes" trials, but only by 16 msec on "no" trials (see Table 1). The 16-msec increase on "no" trials may reflect general inhibitory effects, as well as the need to discriminate both location and form on the word and nonword trials.

Table 1

Experiment 1: Mean Response Time in Milliseconds (RT) and Percent Error Rate (PE) by Response Required and Display Type

\begin{tabular}{cccccccccc}
\hline & \multicolumn{9}{c}{ Display Type } \\
\cline { 2 - 8 } & \multicolumn{2}{c}{ Single Letter } & \multicolumn{2}{c}{ Repeated Letter } & \multicolumn{2}{c}{ Nonword String } & \multicolumn{2}{c}{ Word String } \\
\cline { 2 - 9 } Response Required & RT & PE & RT & PE & RT & PE & RT & PE \\
\hline "Yes" (Target Present) & 718 & 3.10 & 726 & 2.95 & 745 & 3.88 & 769 & 3.00 \\
"No" (Target Absent) & 771 & 2.78 & 767 & 2.68 & 774 & 3.12 & 797 & 2.56 \\
All Trials & 745 & 2.94 & 747 & 2.81 & 759 & 3.50 & 783 \\
\hline
\end{tabular}


As expected, precuing the location of the critical letter eliminated the word superiority effect. Whether it reversed the effect and made letter detection easier with nonwords than with words is less clear. Mean RT was $24 \mathrm{msec}$ longer for words than for nonwords, and, although this difference is not significant, it is too large to dismiss. Therefore, we must be content to retain, rather than accept, the null hypothesis in the present case. It is conceivable that words both helped and hurt processing and that the opposing effects largely canceled out each other. As a familiar pattern unit, the word may resist analysis into letter components but at the same time may aid in interpreting or locating a particular letter, and it may produce less response competition because it is a unitary pattern. Which of these aspects is dominant may depend upon the task used. O'Hara and Eriksen (1979) found that an extraneous trigram, placed between two letters that had to be compared, interfered less with the detection of a match between the two letters when it was a word rather than a nonword, presumably because as a word it could be encoded as a single unit rather than as a set of letters. In a task in which treating the letter string as a whole could improve performance (via redundancy gain), Silverman (1976) found that words were processed as integral stimuli, and nonwords or consonant strings, as separable stimuli. However, when the task required filtering out the other letters and attending only to the first letter, as in the present experiments, Silverman (1977) found performance to be no worse on words than on nonwords. "The total absence of interference in the word-filtering task suggests that visually presented one-syllable words are not integral stimuli" (p. 104).

Word RT may have exceeded nonword RT in the present case because subjects felt more need to be careful and accurate on words than on nonwords. Errors were higher on nonwords than on words, and the difference in RT thus may simply reflect a shift in the speed-accuracy tradeoff between words and nonwords. Words and nonwords were presented on separate blocks, so subjects could easily have adjusted their response criteria somewhat differently for the two types of displays.

\section{EXPERIMENT 2}

Experiment 2 provided an additional test of whether processing is faster or slower with repeated-letter than with single-letter displays. The repeated-letter condition may have had no effect in Experiment 1 because the subject's fixation was held very close to the leftmost letter in the multiletter string (Johnson, Note 2). Disruptive effects of the added letters were evident on words and nonwords but might have been so weakened on repeated-letter displays as to be fully canceled out by facilitative effects. In Experiment 2, therefore, there was no fixation. A rectangle on a prior masking array indicated where a letter or a group of letters would be shown. Subjects thus were free to fixate (and apply their maximum acuity, etc.) on any portion of the array that they chose, whether the first letter, the center letter, or some other.

Another possible reason for finding no effect in Experiment 1 is that the target letter was not spoken to the subject, as in Johnson's (1975) case, but was presented in visual form. If the target letter were encoded in a visual form, then our procedure may have approximated a simultaneous comparison condition. With simultaneous rather than successive comparison, words and other multiletter strings seem to be treated as collections of letters rather than as unitary patterns (Marmurek, 1977). In Experiment 2, therefore, subjects were told to say the target letter out loud when they saw it.

The nonwords used in Experiment 1 were somewhat meaningful. Many contained vowels and familiar letters sequences, which may have made it easy to pronounce them and treat them as wholes. In Experiment 2, a less meaningful extraneous-letters string, composed solely of randomly chosen consonants, was used. The intent was to test to make sure that our procedures would reveal an increment in RT for the extraneous-letters displays even when they formed meaningless strings. We wanted to rule out the possibility that the lack of an increment in RT for repeatedletter displays was not due simply to the insensitivity of our procedure to such factors as response competition and the need to discriminate location as well as form.

\section{Method}

The equipment, stimulus materials, and procedure were the same as in Experiment 1, with certain exceptions. There were three blocks (single letter, repeated letter, consonant strings) of 117 trials each, or 351 trials in all. Each of the six possible orderings of the three blocks was used for six subjects each. Trials were ordered randomly within each block, separately for each of the six groups. The consonant strings were devised by randomly permuting nine instances each of 13 consonants $(B, C, D, F, G$, $\mathrm{H}, \mathbf{L}, \mathbf{M}, \mathbf{N}, \mathbf{P}, \mathbf{R}, \mathbf{S}, \mathrm{T})$ within each of the four letter positions, with the constraint that no consonant appear more than once within a particular consonant string.

No fixation mark was used. Instead, a mask containing a special rectangle $(8.5 \mathrm{~mm}$ wide $\times 4.0 \mathrm{~mm}$ high) was presented during the 1.5 -sec interval between the presentation of the target letter (which subjects were asked to say out loud) and the display. The mask had three rows of six nonsense symbols each. The nonsense symbols (an uppercase $X$ superimposed on an uppercase $O$ ) were spaced as far apart on each row as the letters in the multiletter displays, and the vertical separation between rows was $2 \mathrm{~mm}$. In overall extent, the noise array was $12 \mathrm{~mm}$ wide $\times 11 \mathrm{~mm}$ high. The special rectangle enclosed the middle four nonsense symbols of the middle row of the mask, which is where the display letter(s) later appeared.

There were 36 subjects. Data from several additional subjects were discarded because of failure to follow the instructions, excessive errors ( $10 \%$ or more), or equipment failure. 
Table 2

Experiment 2: Mean Response Time in Milliseconds (RT) and Percent Error Rate (PE) by Response Required and Display Type

\begin{tabular}{llccccc}
\hline & \multicolumn{4}{c}{ Display Type } \\
\cline { 2 - 6 } & \multicolumn{2}{c}{ Single Letter } & \multicolumn{2}{c}{ Repeated Letter } & \multicolumn{2}{c}{ Consonant String } \\
\cline { 2 - 6 } Response Required & RT & PE & RT & PE & RT & PE \\
\hline "Yes" (Target Present) & 698 & 1.90 & 689 & 2.64 & 743 & 3.05 \\
"No" (Target Absent) & 755 & 3.14 & 753 & 3.40 & 767 & 3.09 \\
All Trials & 727 & 2.52 & 721 & 3.02 & 755 \\
\hline
\end{tabular}

\section{Results}

As Table 2 shows, RT was significantly shorter on "yes" (match) than on "no" (mismatch) trials [718 vs. $761 \mathrm{msec} ; \mathrm{F}(1,30)=23.61, \mathrm{p}<.001]$ and on noextraneous-letters trials (single-letter and repeatedletter conditions combined) than on extraneous-letters trials (consonant strings) [724 vs. $755 \mathrm{msec} ; \mathrm{F}(1,30)$ $=8.96, \mathrm{p}<.01]$. The latter two variables also interacted significantly $[F(1,30)=6.96, p<.025]$, the increment in RT on extraneous-letters trials being much larger on target-present trials $(50 \mathrm{msec})$ that on target-absent trials $(13 \mathrm{msec})$. There were no significant main effects or interactions on error rate (see Table 2).

Separate analyses revealed no significant differences between the single-letter and repeated-letter conditions, either on RT ( 727 vs. $721 \mathrm{msec}, \mathrm{F}<1)$ or on errors $(2.52 \%$ vs. $3.02 \%)$. Separate comparisons between the consonant-string condition and each of the no-extraneous-letters conditions (single letter, repeated letter) revealed the same pattern of significant RT main effects and interactions as the main analysis.

\section{Discussion}

As in Experiment 1, there was no significant increment in RT for the repeated-letter displays. In fact, they were processed $6 \mathrm{msec}$ faster than the singleletter displays. A significant increment in RT was found for the extraneous-letters displays, though. Thus, providing a freer fixation, having the target spoken aloud beforehand, and using meaningless extraneousletters displays did not change the basic pattern of results obtained in Experiment 1.

Three findings converge on response competition, rather than on lateral interference or initial attempts to encode the string as a unit, as the main reason that added letters generally hurt performance. First, when made identical to the critical letter, so that response competition was removed, the added letters did not hurt performance. Second, when made to differ from the critical letter, so that a consonant string was formed, the added letters did hurt performance. The consonant string, being meaningless and unpronounceable, should have discouraged any attempts to encode it as a unit before encoding the individual letters, but its added letters, even if encoded individually, still would have provided response competition with the critical letter. Third, the increase in RT on consonant strings was much larger on "yes" trials $(50 \mathrm{msec})$, where the added letters signaled the incorrect response, than on "no" trials $(13 \mathrm{msec})$, where the added letters signaled the correct response and only the need to discriminate both location and form might have slowed processing. A similar interaction was evident, though not significant, in Experiment 1. The Yes-No by Extraneous vs. No-Extraneous interaction was significant not only in Experiment 2, but also for Experiments 1 and 2 analyzed together $[F(1,70)=9.46, p<.01]$.

\section{EXPERIMENT 3}

Experiment 3 provided yet another test of whether the repeated-letter and single-letter displays are processed in the same manner, that is, as individual letters and with the first letter resolved determining the response. It may be that they are processed differently, but that the close spacing of letters in Experiments 1 and 2 caused the added identical letters to produce as much disruption (i.e., from lateral interference and from attempts at encoding the string as a unit) as facilitation. To reduce the effects of lateral interference and to make the letter positions easier to discriminate and treat as separate entities, the letters in Experiment 3 were spaced further apart. Otherwise, the method was the same as in Experiment 2 . The intent was to retain the benefits of the added information provided by the repeated letters, but to eliminate any costs associated with them.

\section{Method}

The method was the same as in Experiment 2, except for the increase in letter spacing. A blank letter separated each of the four letters in the repeated-letter and consonant strings, which thus occupied the same extent as a seven-letter item would have in Experiments 1 and 2. The visual-noise array was expanded to three rows of 11 nonsense symbols each. The inner rectangle was enlarged so as to enclose the center 9 nonsense symbols of the middle row. The four letters of the repeated-letter and consonant strings coincided in location with Positions $2,4,6$, and 8 of the 9 nonsense symbols; the letter in the single-letter condition appeared at Position 2.

There were 36 subjects. Data from several additional subjects were discarded because of failure to follow the instructions, excessive errors ( $10 \%$ or more), or equipment failure.

\section{Results}

As Table 3 shows, RT was significantly shorter on "yes" than on "no" trials [751 vs. 828 msec; F 1,30 $=48.44, p<.001]$ and on no-extraneous-letters trials 
Table 3

Experiment 3: Mean Response Time in Milliseconds (RT) and Percent Error Rate (PE) by Response Required and Display Type

\begin{tabular}{ccccccc}
\hline & \multicolumn{5}{c}{ Display Type } \\
\cline { 2 - 7 } & \multicolumn{2}{c}{ Single Letter } & \multicolumn{2}{c}{ Repeated Letter } & \multicolumn{2}{c}{ Consonant String } \\
\cline { 2 - 7 } Response Required & RT & PE & RT & PE & RT & PE \\
\hline "Yes" (Target Present) & 719 & 2.02 & 746 & 1.74 & 769 & 2.16 \\
"No" (Target Absent) & 794 & 2.00 & 812 & 2.24 & 853 & 2.38 \\
All Trials & 757 & 2.01 & 779 & 1.99 & 811 & 2.27 \\
\hline
\end{tabular}

(single-letter and repeated-letter conditions combined) than on extraneous-letters trials (consonant strings) [768 vs. $811 \mathrm{msec} ; \mathrm{F}(1,30)=7.20, \mathrm{p}<.025]$. The interaction between the latter two variables was not significant; it was even opposite in direction to that found in Experiments 1 and 2. Extraneous letters increased RT somewhat more on target-absent "no" trials $(50 \mathrm{msec})$ than on target-present "yes" trials $(36 \mathrm{msec})$. There were no significant main effects or interactions on error rate (see Table 3 ).

A separate analysis revealed a marginally significant difference between the single-letter and repeated-letter condition RTs [757 vs. $779 \mathrm{msec} ; \mathrm{F}(1,30)=2.77, \mathrm{p} \approx$ .10]. Separate comparisons between the consonantstring condition and each of the no-extraneous-letters conditions revealed a significant $\mathrm{RT}$ difference with the single-letter condition [811 vs. $757 \mathrm{msec} ; F(1,30)$ $=10.69, \mathrm{p}<.01]$ but only a marginally significant RT difference with the repeated-letter condition [811 vs. $779 \mathrm{msec} ; \mathrm{F}(1,30)=3.16, \mathrm{p}<.10 \mathrm{]}$.

\section{Discussion}

Experiment 3 confirmed Experiment 2 by revealing a significant increment in RT on consonant-string displays. Less clear were the results on repeated-letter strings, whose RT exceeded that of single-letter displays by $22 \mathrm{msec}$. This increment was only marginally significant, but cannot be lightly dismissed. It may be the sort of large fluctuation that can be expected to occur by chance alone every so often. Averaging across Experiments 1, 2, and 3, mean RT for the repeatedletter condition exceeded that for the single-letter condition by only $6 \mathrm{msec}$.

Equally likely, the increased spacing in Experiment 3 , while intended to ease the processing of repeatedletter displays, actually made it more difficult. There was no fixation point, and fixing one's gaze on a particular letter may have occurred less frequently with the spread-out repeated-letter string than with the single-letter display. The increased spacing per se, though, probably did not hurt processing. Even with the added spacing, the four-letter string subtended only about $1 \mathrm{deg}$ of visual angle. The extra spacing, though, did not provide the .25- to .50-deg separation between letters needed to fully eliminate the contour interactions which might harm visual acuity (Flom, Weymouth, \& Kahneman, 1963). However, the absence of any increment in RT on repeated- letter strings in Experiments 1 and 2, where letters were spaced even closer together, suggests that contour interactions had little effect. Furthermore, when Eriksen and Eriksen (1979, Experiment 2) varied the spacing over an even wider range (.06 to 1.0 deg between letters) but provided a fixation point at the central, critical letter, they found no tendency for the added compatible letters to increase RT, regardless of spacing.

Several findings indicate that in Experiment 3, with its special conditions (i.e., increased spacing with no fixation point), processing was generally altered and made more difficult. The 50-msec increase in overall RT from Experiment 2 and the $12-\mathrm{msec}$ increase in the effect of the consonant-string display, while not significant, are suggestive. More definite evidence indicating a change in processing is a significant Experiment by Yes-No interaction on $\operatorname{RT}[F(2,105)=4.61$, $\mathrm{p}<.025]$. The tendency for "no" RT to exceed "yes" RT was much stronger in Experiment $3(78 \mathrm{msec})$ than in Experiment $1(38 \mathrm{msec})$ or Experiment $2(42 \mathrm{msec})$. People seem generally less willing to accept a mismatch than a match, without further checking, owing perhaps to differential effects of noise in processing (Krueger, 1978); the greater tendency to recheck "no" responses in Experiment 3 thus suggests that noisier or more difficult conditions were experienced there. Errors were slightly fewer in Experiment 3 (cf. Tables 1, 2, and 3), though, so it is possible that the subjects there were simply more careful in general and on "no" responses in particular.

There also was a significant Experiment by YesNo by Extraneous vs. No-Extraneous interaction on $\mathrm{RT}[\mathrm{F}(2,105)=4.28, \mathrm{p}<.025]$. In Experiments 1 and 2 , the increment in RT for extraneous-letters trials was more than twice as large on "yes" trials as on "no" trials, which is in accord with the response competition explanation. In Experiment 3, by contrast, the increment was only about two-thirds as large on "yes" trials as on "no" trials. The irrelevant letters were farther away from the leftmost, relevant position in Experiment 3, which might explain why they produced a general, rather than a specific, interference.

\section{CONCLUSIONS}

With the generally aberrant results of Experiment 3 excluded, the present study provided several lines of 
evidence which indicate that response competition, along with the extra effort needed to take location into account, can explain why added letters typically hurt letter detection. There is no need to postulate additional mechanisms, such as interactive or inhibitory channels (Bjork \& Murray, 1977; Estes, 1972, 1974) or attempts to encode the letter string as a unit (Johnson, 1975, 1977), to explain the disruption. The results thus provide support for the parallel, independent channels model (Eriksen \& Spencer, 1969; Gardner, 1973; Shiffrin \& Geisler, 1973).

When the added letters on a particular block of trials were identical to the critical letter in the leftmost position, no disruption was evident. Averaging across the present three experiments, the repeated-letter trials exceeded the single-letter trials by only $6 \mathrm{msec}$ in RT and .12\% in errors. Eriksen and Eriksen (1979, Experiment 2) found comparably slight fluctuations in RT when they added physically similar, compatible letters to the display. Bjork and Murray (1977) said that when RT is the primary dependent variable and stimuli are exposed for relatively long durations, inhibitory effects at the perceptual level may be obscured by strong effects at the decision level. In reply, one might ask whether perceptual interference found with near-threshold stimulus presentation is all that comparable to effects found with more normal presentation. Furthermore, the stability of the present data indicates that there is surprisingly little variability at the decision or response level that might have obscured effects at the perceptual level. In Experiments 1 and 2, as well as the four data points presented in Eriksen and Eriksen (1979, Experiment 2), RT for the repeated-letter display consistently fell within 10 msec of RT for the single-letter display, and it was just as likely to show a decrement as an increment. The somewhat larger increment in Experiment 3 most likely reflects peculiarities in the procedure rather than a true perceptual effect. Taken together, the evidence justifies acceptance of the null hypothesis: Adding identical or physically similar, compatible letters does not disrupt performance at the perceptual level, in contrast to Bjork and Murray's conclusions.

To obtain the null effect, several conditions seem to be necessary. Judging from the outcome of Experiment 3, a definite fixation point must be present, especially if the letters are spaced apart and a random gaze is unlikely to register a letter. The compatible or identical added-letter trials apparently must be blocked separately, as was done in the present study and in Eriksen and Eriksen (1979, Experiment 2). The null effect typically is lost and a definite increment in RT is found, when repeated-letter trials are intermixed with extraneous-letters trials (Eriksen \& Schultz, 1979; Johnson, 1977, Note 1). Intermixing of trials also may account for the increase in errors which Bjork and Murray (1977) found when they added an identical letter to the display. When trials are intermixed, subjects are forced to attend to both form and location on all trials, in order to base their decisions solely on the critical letter. When trials are blocked, subjects need attend only to form on repeated-letter trials.

If response competition is so crucial a factor, then why doesn't adding identical or compatible letters actually reduce $\mathrm{RT}$, rather than merely prevent an increment in RT? Perhaps such a gain was present, but was exactly cancelled out by disruption due to lateral interference or the attempt to encode the string as a unit. An exact matching of two opposing effects seems quite unlikely, however. More likely (and more parsimoniously), there was no gain to be canceled out -that is, processing proceeded in parallel at the same rate for all letters in the string, so the first letter to be resolved was seen no faster when several identical letters were presented than when a single letter was presented.

If adding extraneous letters slows processing because location as well as form must be considered, then why cannot this factor alone account for the increase in RT? Why postulate a role for response competition, too? If attention is directed to a particular precued location, why should the contents of adjacent positions matter? The four-letter displays in the present study all fell within the irreducible minimum extent of $1 \mathrm{deg}$ to which attention seemingly may be narrowed or focused (Eriksen \& Hoffman, 1973), and considerable processing may have been done involuntarily on the extraneous added letters. Thus, even if the added letters were always tagged at the decisional level as not being in the critical position, they still may have been processed deeply enough at earlier stages so as to have provided some response competition. It should be possible to dissociate the disruption due to having to take location into account from that due to response competition. For example, the 20 - to 30 -msec increment typically found on repeated-letter displays that are intermixed with extraneous-letters trials may be attributed to the location factor, and subtracting it from the much larger increment found on extraneousletters displays (Eriksen \& Eriksen, 1979, Experiment 2; Johnson, 1977, Note 1) would reveal the increment due to response competition alone.

In Experiments 1 and 2, the extraneous letters increased RT much more on "yes" trials, where they signaled the incorrect response, than on "no" trials, where they signaled the correct response. If we assume that response compatibility on the "no"trials produced no gain, then the small increment on those trials (16 msec in Experiment 1; $13 \mathrm{msec}$ in Experiment 2) would be assigned to the location factor, whereas the larger increment on "yes" trials (35 msec in Experiment 1; 50 msec in Experiment 2) would be attributed to both the location factor and response competition. Thus, in Experiments 1 and 2, the location factor apparently increased RT by about $15 \mathrm{msec}$, and response competition increased $\mathrm{RT}$ by about $30 \mathrm{msec}$. 
The fact that meaningless, unpronounceable consonant strings produced as large an increment in $\mathrm{RT}$ in Experiments $2(31 \mathrm{msec})$ and $3(43 \mathrm{msec})$ as did the nonwords and words in Experiment $1(25 \mathrm{msec})$ suggests that letter detection in a multiletter string did not suffer because the string tended to be treated as a single unit or pattern. The increment in RT was larger for words than for nonwords in Experiment 1, but this difference was not significant. Several factors may have to be disentangled to determine whether words, as more unitary patterns, tend in some respect to conceal, rather than reveal, their letters. Words, if treated as single units rather than as collections of letters, would be hurt insofar as they less readily give up their letter components, but helped insofar as losing the extraneous added letters to the word gestalt should result in less response competition (cf. O'Hara \& Eriksen, 1979).

\section{REFERENCE NOTES}

1. Johnson, N. F. Personal communication, September 1979. 2. Johnson, N. F. Personal communication, December 1977.

\section{REFERENCES}

BJork, E. L., \& Estes, W. K. Detection and placement of redundant signal elements in tachistoscopic displays of letters. Perception \& Psychophysics, 1971, 9, 439-442.

BJork, E. L., \& Murray, J. T. On the nature of input channels in visual processing. Psychological Review, 1977, 84, 472-484.

Egeth, H. E., \& Santee, J. L. Conceptual and perceptual components of interletter inhibition. Journal of Experimental Psychology: Human Perception and Performance, 1980, in press.

Eriksen, C. W., \& Eriksen, B. A. Target redundancy in visual search: Do repetitions of the target within the display impair processing? Perception \& Psychophysics, 1979, 26, 195-205.

Eriksen, C. W., \& Hoffman, J. E. The extent of processing of noise elements during selective encoding from visual displays. Perception \& Psychophysics, 1973, 14, 155-160.

ERIKSEN, C. W., \& LA PPIN, J. S. Internal perceptual system noise and redundancy in simultaneous inputs in form identification. Psychonomic Science, 1965, 2, 351-352.

ERIKSEN, C. W., \& Schultz, D. W. Information processing in visual search: A continuous flow conception and experimental results. Perception \& Psychophysics, 1979, 25, 249-263.

Eriksen, C. W., \& Spencer, T. Rate of information processing in visual perception: Some results and methodological considerations. Journal of Experimental Psychology Monograph, 1969, 79 (2, Pt. 2).

Estes, W. K. Interactions of signal and background variables in visual processing. Perception \& Psychophysics, 1972, 12, 278-286.

Estes, W. K. Redundancy of noise elements and signals in visual detection of letters. Perception \& Psychophysics, 1974, 16, 53-60.

Flom, M. C., Weymouth, F. W., \& Kahneman, D. Visual res- olution and contour interaction. Journal of the Optical Society of America, 1963, 53, 1026-1032.

Gardner, G. T. Evidence for independent parallel channels in tachistoscopic perception. Cognitive Psychology, 1973, 4, 130-155.

GARNER, W. R. The processing of information and structure. Potomac, Md: Erlbaum, 1974.

Henderson, L. Do words conceal their component letters? A critique of Johnson (1975) on the visual perception of words. Journal of Verbal Learning \& Verbal Behavior, 1975, 14, 648-650.

Johnson, N. F. On the function of letters in word identification: Some data and a preliminary model. Journal of Verbal Learning \& Verbal Behavior, 1975, 14, 17-20.

Johnson, N. F. A pattern-unit model of word identification. In D. LaBerge \& S. J. Samuels (Eds.), Basic processes in reading: Perception and comprehension. Hillsdale, N.J: Erlbaum, 1977.

Johnston, J. C., \& McClelland, J. L. Perception of letters in words: Seek not and ye shall find. Science, 1974, 184, 1192-1193.

KRUEGER, L. E. Familiarity effects in visual information processing. Psychological Bulletin, 1975, 82, 949-974.

Krueger, L. E. A theory of perceptual matching. Psychological Review, 1978, 85, 278-304.

Krueger, L. E., \& Shapiro, R. G. Letter detection with rapid serial visual presentation: Evidence against word superiority at feature extraction. Journal of Experimental Psychology: Human Perception and Performance, 1979, 5, 657-673.

Marmune K, H. H. C. Processing letters in words at different levels. Memory \& Cognition, 1977, 5, 67-72.

Massaro, D. W., \& Klitzke, D. Letters are functional in word identification. Memory \& Cognition, 1977, 5, 292-298.

O'HARA, W., \& ERIKSEN, C. W. Word unitization examined using an interference paradigm. Bulletin of the Psychonomic Society, 1979, 14, 81-84.

Shiffrin, R. M., \& Geisler, W. S. Visual recognition in a theory of information processing. In R. L. Solso (Ed.), Contemporary issues in cognitive psychology: The Loyola Symposium. Washington: Winston, 1973.

Silverman, W. P. Can "words" be processed as integrated units? Perception \& Psychophysics, 1976, 20, 143-152.

Silverman, W. P. Are visually presented one-syllable words integral stimuli? Bulletin of the Psychonomic Society, 1977, 9, 103.105.

Sloboda, J. A. Decision times for word and letter search: A wholistic word identification model examined. Journal of Verbal Learning \& Verbal Behavior, 1976, 15, 93-101.

Stoboda, J. A. The locus of the word-priority effect in a targetdetection task. Memory \& Cognition, 1977, 5, 371-376.

TAYLOR, D. A. Time course of context effects. Journal of Experimental Psychology: General, 1977, 106, 404-426.

Thonndike, E. L., \& Lorge, I. The teacher's word book of 30,000 words. New York: Teachers College, Columbia University, Bureau of Publications, 1944.

Wolford, G. L., Wessel, D. L., \& Estes, W. K. Further evidence concerning scanning and sampling assumptions of visual detection models. Perception \& Psychophysics, 1968, 3, 439-444.

(Received for publication January 22, 1980; revision accepted March 20, 1980.) 